\title{
Analysis of Precipitation Concentration Index (PCI) for Awka Urban Area, Nigeria
}

Ezenwaji EE ${ }^{1}$, Nzoiwu $\mathrm{CP}^{1}$ and Chima $\mathrm{GN}^{2}$

${ }^{1}$ Department of Geography and Meteorology, Nnamdi Azikiwe University, Awka, Nigeria

${ }^{2}$ Department of Geography and Environmental Management, Abia State University, Uturu, Nigeria

${ }^{*}$ Corresponding author: Emma Emeka Ezenwaji, Department of Geography and Meteorology, Nnamdi Azikiwe University, Awka, Nigeria, Tel: +234803609088; E-mail: emmaezenwaji@gmail.com

Received date: December 20, 2017; Accepted date: December 26, 2017; Publication date: December 30, 2017

Copyright: (C) 2017 Ezenwaji EE, et al. This is an open-access article distributed under the terms of the Creative Commons Attribution License, which permits unrestricted use, distribution, and reproduction in any medium, provided the original author and source are credited.

\begin{abstract}
Causes and consequences of climate variability of which the fluctuation in rainfall amounts over time represent an important indicator is indeed an area that has continued to generate research attention. The aim of this paper is, therefore, to evaluate the concentration and variability of rainfall in time using Precipitation Concentration Index ( $\mathrm{PCl}$ ) based on monthly precipitation over 38 years period (1976-2013) and its implications for flooding and water supply in the town. Data for the study were collected from NIMET, Lagos. The PCl was calculated for annual, seasonal and decadal scales using annual, wet and dry season equations. Result shows that annual $\mathrm{PCl}$ value range from the lowest of 12 in 1976 to the highest of 20 in 1987 . About $78 \%$ of the years were characterized by $\mathrm{PCl}$ values that fall within moderate range, an indication of moderate precipitation distribution within the 38-year period, while $24 \%$ of the years recorded annual value within the irregular range indicating an irregular rainfall distribution and concentration across the months. Again, the fact that many months have $\mathrm{PCl}$ values within $\geq 16.7$ is a further manifestation that almost $90 \%$ of the rainfall occurred in 6 months. These results show that the area is having reasonable floods with consequent pollution of the surface water bodies as well as soil erosion as observed in the town. It is, therefore, recommended that the Awka Capital Territory Development Authority (ACTDA) should take cognizance of this result in the planning of the new layouts and redevelopment of the old areas of the town.
\end{abstract}

Keywords: Annual; Concentration; Decadal; Precipitation and seasonal

\section{Introduction}

Prospects of climate change due to global warming have moved from the realm of speculation to general acceptance [1]. It has become a dominant global environmental problem in the last three decades. This realization has led to questions about the relative effects of shifts in climate conditions on natural ecosystems and processes. Odjugo $[2,3]$ reported that global warming and decreasing rainfall together with erratic pattern of rainfall will produce a minimal recharge of ground water resources, wells, lakes and rivers in most parts of the world especially Africa, thereby creating water stress. This change in the nature of precipitation over an area that accompany climate change has the potential to alter some aspects of the hydrological cycle [4] and to cause shifts in a number of natural process such as ground water recharge, water availability, modification of fluvial regimes, the likelihood and severity of erosion, increased flood risk and variations in sizes of surface water systems [5-8].

With recent flood devastation of some parts of Europe with France recording an all- time high precipitation value of $192 \mathrm{~mm}$ for the month of May above the $92 \mathrm{~mm}$ normal, this study is very timely. With global warning, Le Trent et al in Jiang et al noted that precipitation intensity, amounts and patterns are expected to change while extreme weather events such as drought and flood are expected to occur more frequently. Precipitation extremes such as rainstorms and particularly heavy precipitation events occurring over a few days that accounts for high percentages of the annual total, are directly responsible for flood occurrences and will bring more frequent disasters for human society. This was the case of France with its Seine River rising to about 6 meters due to a few days rainfall. Therefore, precipitation total on annual, seasonal or monthly scales are key elements affecting water availability, but precipitation concentration in time also plays a decisive role [5]. The incidence of erratic rainfall has been a major climatic event in most parts of the world, Nigeria inclusive. For example, the 2012 flood problem in Nigeria which left a lot of destruction in its trail has continued to be remembered. The study of precipitation concentration for major urban areas in Nigeria including Awka has now become of concern to government and researchers.

Awka, located in the eastern part of Anambra State, South east of Nigeria is characterized by a typical tropical wet and dry climate. There is considerable variation in the total annual rainfall from year to year based on some studies carried out in the study area. Attempts have also been made to study the cycles and periodicities of rainfall in the area [9]. Until now, there has been no detailed study on concentration and variation of rainfall in Awka despite the yearly flood events ranging parts of the town with each rainy season. In this respect, the only attempts made in addition to the study by Ezenwaji et al. [9] were studies to evaluate causes of flooding in the town [10] and study examining the precipitation and water balance characteristics of the town (under review).

However, understanding precipitation variations on various time scales and their correlation is important for assessment of flood risks and for water resource management. Precipitation extremes can, therefore be quantified by the frequency analysis of rainfall series and precipitation heterogeneity indexes [11]. Some straight forward indicators have been employed to evaluate precipitation concentration 
Citation: Ezenwaji EE, Nzoiwu CP, Chima GN (2017) Analysis of Precipitation Concentration Index (PCl) for Awka Urban Area, Nigeria. Hydrol

Page 2 of 6

used to provide information on its variability [5,12]. These indices include Precipitation Concentration Index (PCI) [5,13], Simple Daily Intensity Index, Precipitation Concentration Degree (PCD) and Precipitation Concentration Period (PCP), modified Fourier Index [14], Seasonality Index [11] etc. A higher precipitation concentration represented by greater percentages of the yearly total precipitation in a few rainy days, has the potential to cause flood and also drought phenomena. In the face of recurring flood events within the Awka urban area, almost on annual basis, it is very important to investigate precipitation variation and concentration. As a result, the main aim of this paper is to evaluate the concentration and variability of rainfall in time using PCI and to explore possible relationship between PCI and annual rainfall total; and between PCI and rainy days. The use of PCI is based on recommendations by numerous studies that it provides information on long term total variability in the amount of rainfall received $[5,12,15]$.

\section{Materials and Methods}

\section{Study area}

Awka town is located in the South-Eastern part of Nigeria and in the eastern part of Anambra State. It covers the whole of Awka South Local Government and some parts of Awka North. It is bounded by Latitudes $6^{\circ} 11^{1} \mathrm{~N}$ and $6^{\circ} 17^{1} \mathrm{~N}$ and longitude $7^{\circ} 02^{1} \mathrm{E}$ and $7^{\circ} 08^{1} \mathrm{E}$, Figure 1.

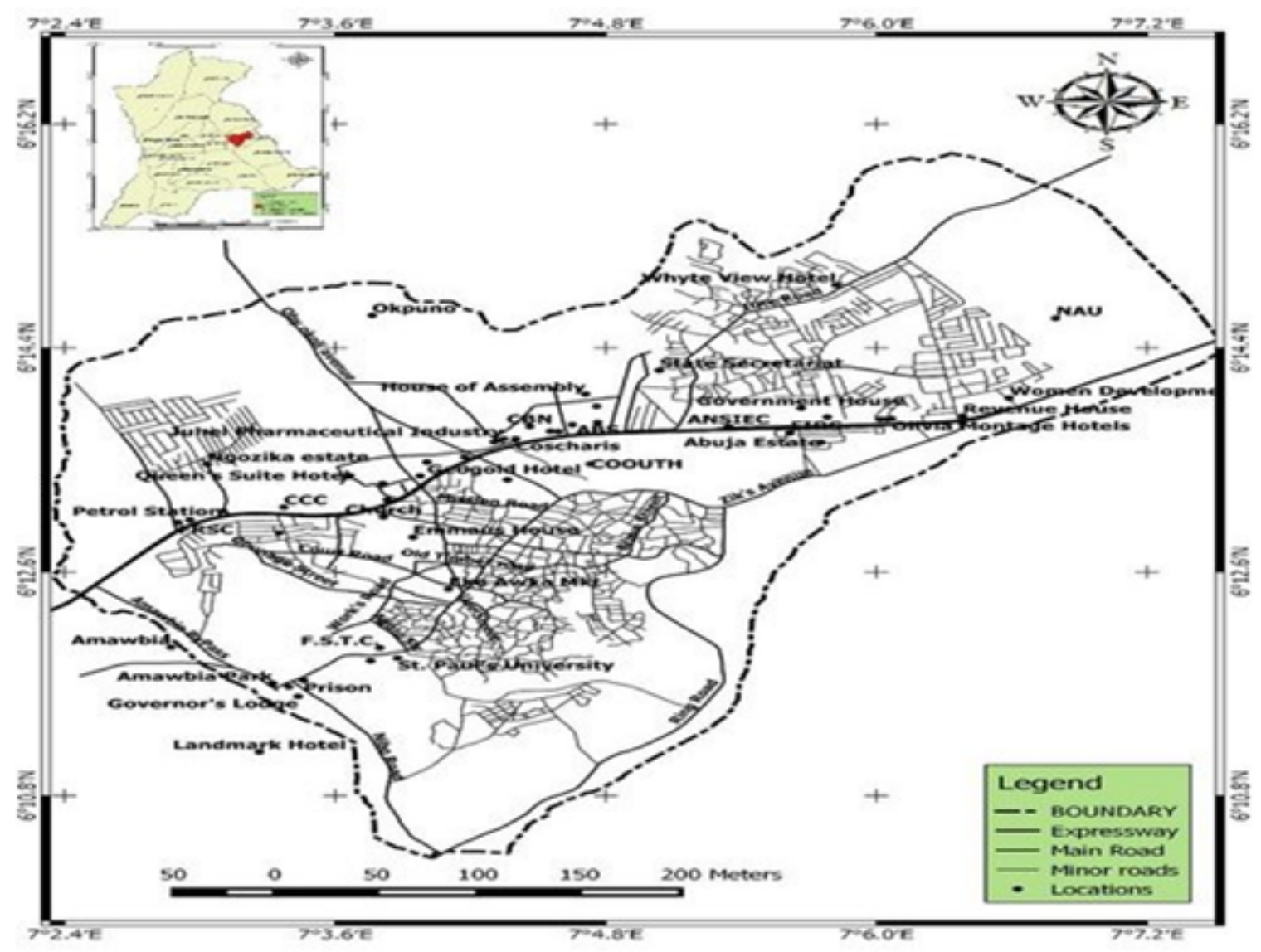

Figure 1: Map of Awka, the study Area.

The topography is characterized by rugged relief and it lies completely on the Awka - Orlu upland [10]. The climate of Awka falls within the tropic wet and dry type based on koppen's classification. The rainfall is patterned in such a manner that the long-wet season occurs normally from April-October while the dry season occurs from November-March. The mean annual rainfall is about $1805 \mathrm{~mm}$ while the maximum and minimum temperatures are $32.1^{\circ} \mathrm{C}$ and $23.5^{\circ} \mathrm{C}$ respectively. In recent times, the onset and cessation period of the rainfall in the study area has been observed to vary over time.

\section{Data collection}

Monthly rainfall dataset was obtained from the Nigerian Meteorological Agency (NIMET) Lagos State. The data was for a period of 38 years (1976-2013). The rainfall data is quite homogenous as there are no gaps to necessitate interpolations.

\section{Data analysis}

PCI of Oliver (1980) further developed by De-Lius et al. [5], has equally been expressed as an indicator of rainfall concentration for annual and seasonal scales (wet and dry seasons). We are using the 
Citation: $\quad$ Ezenwaji EE, Nzoiwu CP, Chima GN (2017) Analysis of Precipitation Concentration Index (PCl) for Awka Urban Area, Nigeria. Hydrol

Page 3 of 6

technique to examine 38-year rainfall data for Awka Urban Area. The equations employed for the purpose $[5,13]$ are written as follows:

$$
\begin{gathered}
P C I_{\text {annual }}=\frac{\sum_{i=1}^{12} P_{i}^{2}}{\left(\sum_{i=1}^{12} P_{i}\right)^{2}} \times 100 \\
P C I_{d r y}=\frac{\sum_{i=1}^{12} P_{i}^{2}}{\left(\sum_{i=1}^{5} P_{i}\right)^{2}} \times 42
\end{gathered}
$$

$$
P C I_{\text {wet }}=\frac{\sum_{i=1}^{12} P_{i}^{2}}{\left(\sum_{i=1}^{7} P_{i}\right)^{2}} \times 58 \quad \text { (3) Where } \mathrm{Pi} \text { is monthly }
$$

precipitation of any month, i.

Equation 1 is for annual PCI while equations 2 and 3 are utilized for the analysis of seasonal scales (rainy and dry seasons). The classification of PCI values according to Oliver (1980) is presented in Table 1.

\begin{tabular}{|l|l|}
\hline $\mathbf{P C l}$ Value & Significance (Temporal Distribution) \\
\hline $\mathrm{PCl} \leq 10$ & Uniform Precipitation Distribution (low precipitation concentration) \\
\hline $\mathrm{PCl}>10 \leq 15$ & Moderate Precipitation Distribution \\
\hline $\mathrm{PCl}>16 \leq 20$ & Irregular Precipitation Distribution \\
\hline $\mathrm{PCl}>20$ & Strong Irregularity of Precipitation Distribution \\
\hline
\end{tabular}

Table 1: PCI range and classification [13].

Furthermore, statistics employed in the analysis include Pearson Product Moment Correlation (PPMC) to establish the relationship between PCI and annual rainfall and further between PCI and number of rainy days. The calculation was performed using the Statistical Package for Social Sciences (SPSS) version 20.

\section{Results}

On annual basis, the result of the PCI calculated for Awka (Figure 2) showed the PCI value range from the lowest value of 12 in 1976 to the highest of 20 recorded in 1987 . The result further showed that $76 \%$ of the years were characterized by a PCI value within the moderate range, an indication of moderate precipitation distribution within these years while $24 \%$ of the years recorded annual PCI value within the irregular range indicating an irregular rainfall distribution/concentration across months of these years.

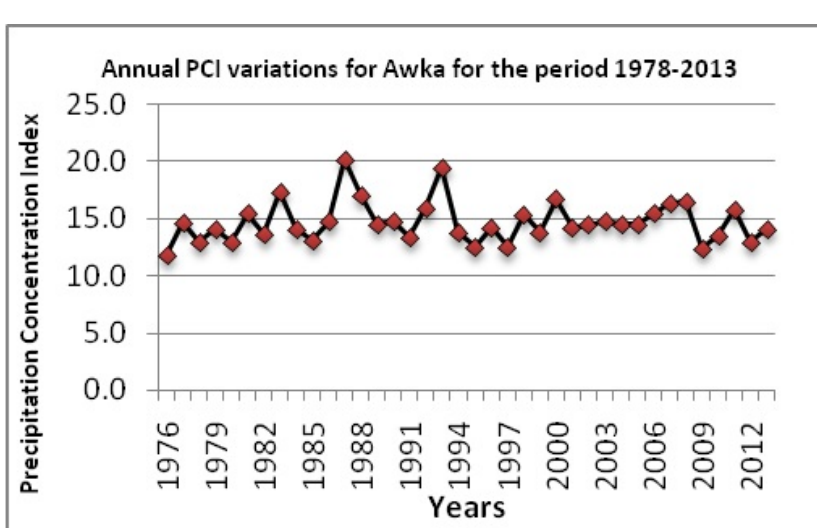

Figure 2: Annual Precipitation Concentration Index for Awka.

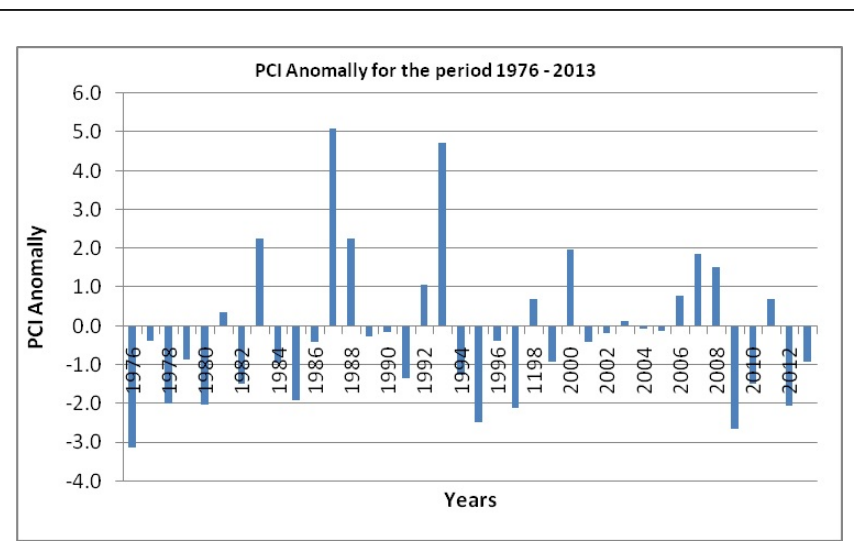

Figure 3: PCI anomally for Awka.

This also indicates that in each of the years for which the PCI value falls within the irregular range, with a PCI value of $\geq 16.7$, precipitation will be concentrated in half of the period [5] i.e., almost $90 \%$ of total annual rainfall occurred in 6 months. The mean annual PCI value for Awka was calculated to be 15; of the 38 years under study, only 12 of those years recorded values above the mean while 26 years were predominantly below the mean (Figure 3 ). Thus, mean rainfall concentration for the period is in the moderate range.

On seasonal scale, the mean annual PCI for the dry season was calculated and found to be 21 (strong irregularity). For the 38 years period, $40 \%$ of the years yielded a PCI value greater than 21 , indexing strong irregularity in rainfall distribution, $37 \%$ of the years showed PCI value within the 11-15 range (moderate rainfall concentration/ distribution) while the remaining $23 \%$ yielded PCI value of the irregularity range. 
Citation: $\quad$ Ezenwaji EE, Nzoiwu CP, Chima GN (2017) Analysis of Precipitation Concentration Index (PCl) for Awka Urban Area, Nigeria. Hydrol Current Res 8: 287. doi:10.4172/2157-7587.1000287

Page 4 of 6

\begin{tabular}{|l|l|l|l|}
\hline $1976-1985$ & 9 & 15 & 13 \\
\hline $1986-1995$ & 9 & 16 & 14 \\
\hline $1996-2005$ & 10 & 15 & 16 \\
\hline
\end{tabular}

Table 2: Mean decadal values of Seasonal and Annual PCI for Awka.

The irregularity in rainfall concentration during the dry season as strongly indicated by the values of PCI in Table 2 is depicted in Figure 4.

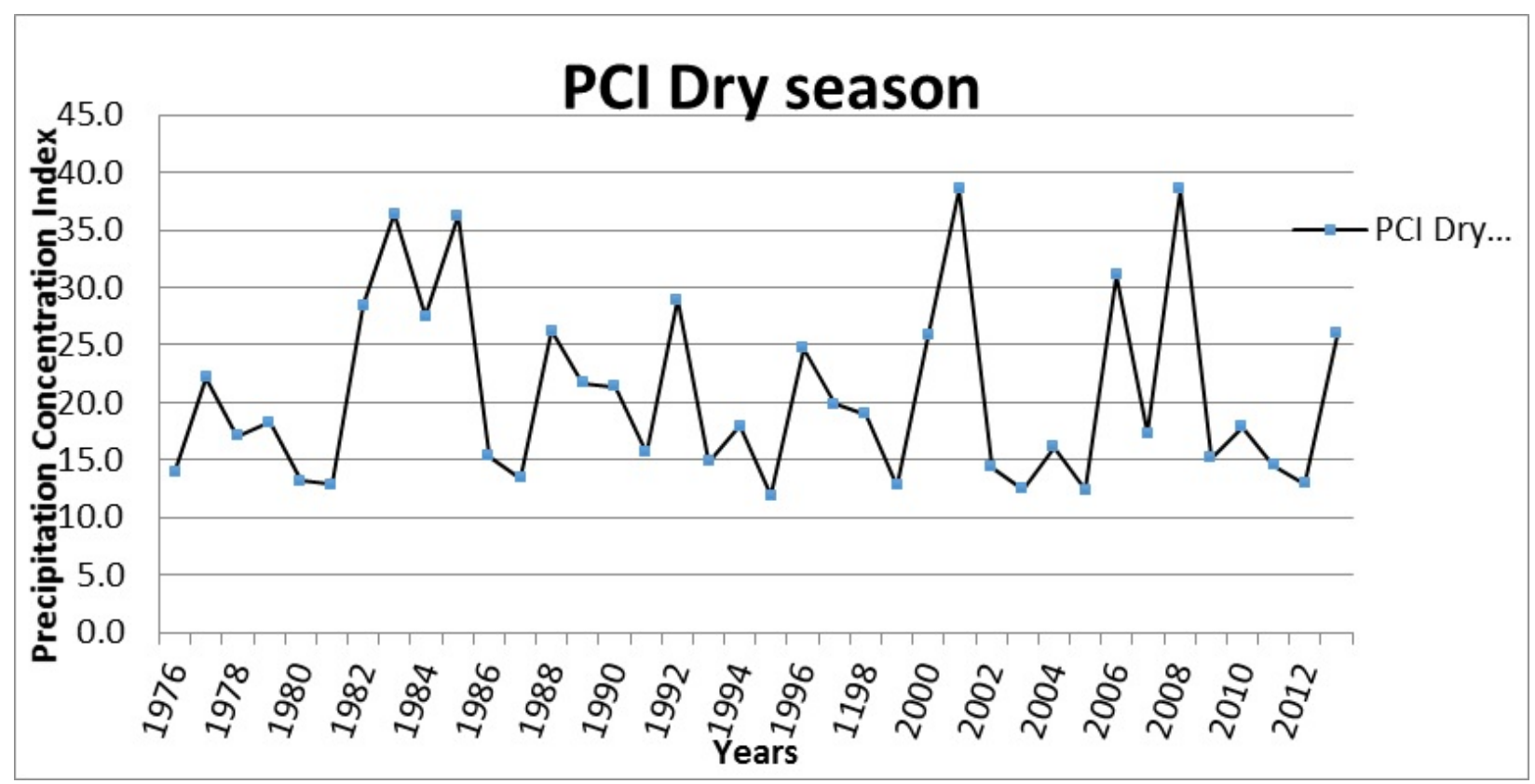

Figure 4: Precipitation Concentration Index for dry season in Awka.

For the wet season, rainfall was generally uniformly distributed with $13 \%$ of the 38 -year period having moderate precipitation concentration while $87 \%$ of these years are characterized by estimated PCI value within the uniform category. In De Luis et al. [5], it was stated that the lowest theoretical value of PCI is 8.3 indicating perfect uniformity in precipitation distribution. The implication is that nearly the same amount of rainfall occurs in each month of the wet season for the $87 \%$ of these years given that the PCI values calculated are $\leq 10$ though none of these years has a perfect uniform precipitation distribution (Table 2, Figure 5).

In addition, the mean annual PCI value calculated for the wet season was found to be within the uniform category $(=9)$.

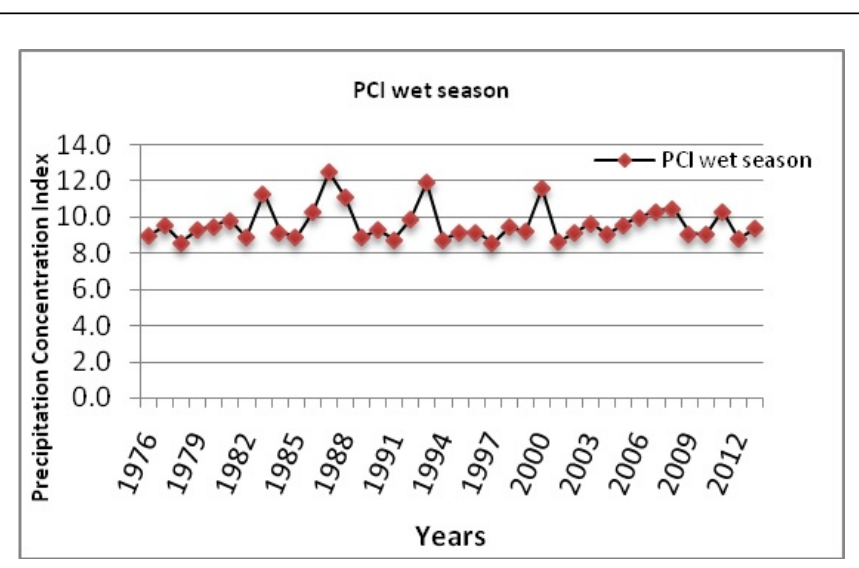

Figure 5: Precipitation Concentration Index for wet season in Awka. 


\section{Decadal variations in PCI Value}

To further investigate the characteristics of PCI in Awka, decadal values were calculated. On the decadal scale, the annual PCI for 19761985 and 1986-1995 fall within the moderate precipitation concentration category giving average value of 13 and14 respectively while the period 1996-2005, with a PCI value of 16 , is characterized by irregularity in precipitation distribution; for the wet season, the PCI value for the 3 decades showed that rainfall was generally uniformly distributed for all the decades; for the dry season, while rainfall concentration was observed to be moderately distributed for the periods 1976 - 1985 and 1996-2005, it is of irregular distribution for the 1986-1995 period. However, for the last period, 2006-2013, PCI for annual, dry season and wet season are 15,13 and 9 respectively.

To further characterize the behaviour of PCI in Awka, a correlation analysis was performed to evaluate its relationship with annual precipitation and number of rain days using PPMC. A negative but not statically significant correlation $(r=-0.06)$ at $p=0.05$ was observed between annual precipitation and annual PCI values at 0.05 confidence level, while with rainy days, a negative and statistically significant correlation at $\mathrm{p}=0.05(\mathrm{r}=-0.63)$ was observed. This implies that PCI is expected to increase with decrease in number of rainy days and decrease in annual rainfall total for Awka.

\section{Discussion}

A good knowledge of critical values of the series of various climatic elements such as rainfall and some of their derived indexes is of great importance in detecting variability which has implications for water resource planning and management, disaster preparedness etc. This study underscores the usefulness of PCI in detecting precipitation concentration and variability. It was observed based on the plot for rainfall and PCI that this climatic variable and the associated index are changing. On annual scales, PCI was found to range from the lowest value of 12 in 1976 to the highest, for the 38 years period under study, of 20 in 1987. This implies that rainfall pattern in the study area is not uniformly distributed but had fluctuated between moderate irregularity and irregular distribution range; $76 \%$ of the years were characterized by PCI value within the moderate range (11-15) while $24 \%$ annual PCI values ranged from 16 to 20 (demonstrating irregular distribution). The implication of such irregular precipitation recorded for the $24 \%$ of the years is that this can have high erosion-potential [16].

In addition, similar observation was not obtained at seasonal scales. Awka is characterized by 5 months of dry season and 7 months of rainy season. For the dry seasons, average annual PCI was found to be 21 (strong irregularity of precipitation distribution) for the 38 years period, $60 \%$ of the years yielded a PCI value above the average of 21 ; $37 \%$ are within the irregular range. The implication of this outcome is wide and varied given the susceptibility of this region to flooding and erosion due to the frail nature of the soil, its profile and underlying geology once exposed (as a result of high human contact with the environment e.g., Urbanization and deforestation) to the vagaries of weather. For the wet season, rainfall is more uniformly distributed, with $87 \%$ the year having PCI of less than 10 while $13 \%$ falls in the moderate category.

However, attempt was made to examine the possible relationship between PCI and number of rain days, and between PCI and annual precipitation using Pearson Product Moment Correlation. PCI was negatively correlated with both variables but, while it is statistically significant with the number of rainy days at $\mathrm{P}=0.05$, it was not significant with annual precipitation. Though the correlation of PCI and annual rainfall is not statistically significant, the negative correlation still indicates that PCI is expected to be large when annual precipitation is low and vice versa. The same applies to the number of rain days which shows a correlation that is statistically significant.

More so, atmospheric precipitation is a key component of water cycle and a main source of all water resources on land; thus, analysis of precipitation characteristics of a place has scientific and practical value. On this note, studies $[5,6,15]$ have variously described precipitation concentration as an index of rainfall variability, water availability and rainfall erosivity. The Awka urban and its peri-urban communities have been experiencing, on annual basis, the biting effects of flooding and erosion. Even when basins and rivers exist to carry flood, heavy rainfall often causes their carrying capacities to be exceeded. Efforts were made in this regard by Ezenwaji et al. [10] to evaluate the contributing factors to flood occurrence in this region and concluded that climatic elements contributed highly in flood occurrence in Awka and the proportion of observed variation in flood occurrence in the Northern parts of Anambra state. This, however, supported the assertion by Agrail [17] that the climatic factors especially rainfall is the most important factor responsible for flooding in the urban area of most tropical countries.

Consequently, despite the persistent case of flooding and erosion within Awka urban area and the surrounding peri-urban communities, no single attempt have been made to evaluate precipitation variability notwithstanding the wide range of problems rainfall variability would cause. Based on the result above, annual rainfall in Awka is not uniformly distributed but can be characterized as being of moderate concentration to irregular precipitation distribution in most of the years and strongly irregular in others. This implies that the tendency is high for rainfall in this region to be heavy and intensive but within a short instance of time. Precipitation of such nature is capable of generating flash flood which could lead to erosion and other water related problems incident in the area. Similarly, given that precipitation variability is capable of modifying fluvial regimes; Nzoiwu [8] remarked that Agulu Lake, a fresh water lake located in Agulu town, a peri-urban community of Awka, lost approximately $17 \%$ of its surface area due to such variability between 1983 and 1988. It was also found that the lowest number of rainy days and annual rainfall for the 38 years period occurred between 1983 and 1988 while highest PCI value occurred in the same period. This shows a strong agreement with the correlation of PCI and number of rainy days, and annual rainfall [18]. Also, there is needing to further investigate the spatial variability in PCI value on all scales for Awka and its region given that precipitation is spatially highly variable.

\section{Conclusion}

This paper has attempted to determine the variability in rainfall condition of Awka using PCI as an index of rainfall concentration and variability. Therefore, the results presented in this study have shown PCI to be a very important input, valuable for water resource planning and management, disaster preparedness, and provides information on water variability for the relevant government agencies and should be taken into account. The implications of such observed change have strong influence on natural process of soil erosion, flooding, fluvial regimes and groundwater recharge. It is, therefore, recommended that the Awka Capital Territory Development Authority (ACTDA) should 
take cognizance of this result in the planning of the new layouts and redevelopment of the old areas of the town.

PCI can, therefore, serve as a warning tool for flooding and erosion within Awka and environs.

\section{References}

1. Stefouli M, Charou E, Katsimpra E (2011) Monitoring Lake Ecosystems Using Integrated Remote Sensing / Gis Techniques: An Assessment in the Region of West Macedonia, Greece. In: Ekundayo EO (ed.) Environmental Monitoring.

2. Odjugo PA (2010) General Overview of Climate Change Impacts in Nigeria. J Hum Ecol 29: 47-55.

3. Odjugo PAO (2010) Regional evidence of climate change in Nigeria Journal of Geography and Regional Planning 3: 142-150.

4. McGuire B, Macon I, Kilburn C (2002) Natural Hazards and Environmental Change. Arnold, London, 13-61.

5. De-Luis M, Gonzales-Hudalgo JC, Brunette M, Longares LA (2011) Precipitation Concentration Changes in Spain 1946-2005. Natural Hazards and Earth Systems Sciences 11: 1259-1265.

6. Adegun O, Balogun I, Adeaga O (2012) Precipitation Concentration Changes in Owerri and Enugu. Hydrology for Disaster Management, special publication of NAHS.

7. Ezemonye MN, Emeribe CN (2011) Correlogram Analysis of Trend and Cycles in Rainfall over Southeastern Nigeria. Pakistan Journal of Social Sciences 8: 325-333.

8. Nzoiwu PC (2015) An Preliminary assessment of the Effects of Climate Variability and Climate change on Agulu Lake, Anambra State. Unpublished Msc Thesis, The University of Ibadan, Oyo State.
9. Ezenwaji EE, Phil-Eze PO, Enete IC, Osuiwu BO (2014) An Analysis of the Cycles and Periodicities of Annual Rainfall over Awka Region, Nigeria. Atmospheric and Climate Sciences 4: 665-671.

10. Ezenwaji EE, Phil-Eze PO, Otti VI, Eduputa BM (2013) Household Water Demand in the Peri-Urban Communities of Awka, Capital of Anambra State, Nigeria. Journal of Geography and Regional Planning 6: 237-243.

11. Kumbuyo CP, Yasuda H, Kitamura Y, Shimizu K (2014) Fluctuation of Rainfall Time Series in Malawi: An Analysis of Selected Areas. Geofizika 31.

12. Apaydin H, Erpul G, Bayramin I, Gabriels D (2006) Evaluation of Indices fo characterizing the distribution and concentration of precipitation: A case for the region of south eastern Anatolia Project, Turkey. J Hydrol 328: 726-732.

13. Oliver JE (1980) Monthly Precipitation Distribution: A Comparative Index. Professional Geographer 32: 300-309.

14. Hernando D, Romana MG (2015) Estimating the Rainfall Erosivity Factor from Monthly Precipitation Data in the Madrid Region (Spain). J Hydrol Hydromech 63: 55-62.

15. Michiels P, Gabriels D, Hartman R (1992) Using the Seasonal and Temporal Precipitation Concentration Index for Characterizing Monthly Rainfall Distribution in Spain. CATENA 19: 43-58.

16. Iskander SM, Rajib MA, Rahman MM (2014) Trending Regional Precipitation Distribution and Intensity: Use of Climatic Indices. Atmospheric and Climate Sciences 4: 385-393.

17. Agrail FD (2009) Rainfall and its Effects in Urban Environment. J Atmos Sci 13.

18. Valli M, Sree KS, Krishna IV (2013) Analysis of Precipitation Concentration Index and Rainfall Prediction in various Agro Climate Zones of Andhra Pradesh, India. Inter Research Journal Env Sci 2: 53-61. 